\title{
eHealth in Europe - Status and Challenges
}

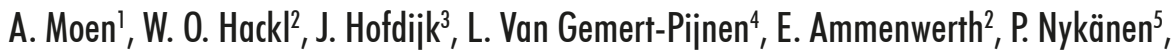 \\ A. Hoerbst ${ }^{2}$ \\ 1 Institute for Health and Society, University of Oslo, Norway \\ ${ }^{2}$ UMIT, University for Health Sciences, Medical Informatics and Technology, Austria \\ ${ }^{3}$ CaseMix, the Netherlands \\ ${ }^{4}$ University of Twente, the Netherlands \\ ${ }^{5}$ School of Information Sciences, University of Tampere, Finland
}

\begin{abstract}
Summary
Objectives: To present European reflections on the concept of etlealth and emerging challenges related to further development of ellealth in Europe.

Methods: A survey with 10 questions was distributed to representatives of the national member associations of the European Federation of Medical Informatics (EFMI).

Results: The results document a shiff from a constricting ICT-orientation to development of the entire health system where eHealth strategies, organizational change, and appropriate technological infrastructure are singled out as important aspects. Conclusion: There are urgent needs to ensure that eHealth strategies and policies for further design and deployment of ellealth applications support sociable services and innovations in health care.
\end{abstract}

\section{Keywords}

eHealth, status and challenges, Europe, survey

Yearb Med Inform 2013:59-63

\section{Introduction}

Over the last years, health informatics respectively medical informatics has matured. The field is committed to improve quality in health care, provide best evidence at the point of need, and also demonstrate benefits across settings, taking advantage of technological opportunities and applications [1]. On the European scene we observe that the terms health informatics, medical informatics, nursing informatics etc. are gradually substituted or used interchangeably with the term eHealth.

Time is overdue to actively promote health technology reflecting science-based evidence to ensure that the tools are deployed according to robust evidence [2, 3]. Such evidence would draw from technological, health professional and social perspectives. There are several reports and surveys, [c.f. 4, 5] providing snapshots and interesting examples for eHealth evolution across Europe. Publications prepared under the leadership of EFMI also points out key eHealth issues. These issues range from user-involvement and experiences of health professionals and patients working and living in ICT enabled environments [6], health informatics opportunities to deploy, evaluate, and adjust healthcare services [7] to internationally oriented policies and programs to support patient safety [8], interoperability for seamless care [9], cross border care, no boundaries perspectives [10], and adequate business models for health technologies [11].

Achievements in eHealth can support future demands within the health care system and improve the quality of life of citizens, patients and health providers'. The objective of this paper is to discuss the concept of eHealth through a European lens, and present challenges with regard to eHealth in Europe based on a survey administered to the national member societies of the European Federation of Medical Informatics (EFMI). We will contribute experience and evidence to discuss current perspectives for eHealth opportunities and challenges identified in Europe.

\section{Methods and Material}

The current study is based on a survey research methodology. Potential participants were asked to answer 10 questions focusing on definitions, trends, challenges and priorities, cultural aspects and links between ICT infrastructure and the health care system, on an operational as well as strategic level. These questions were:

1. What is definition for eHealth is used in your country?

2. What are the key trends and developments in the eHealth domain in your country?

3. What are the main difficulties for the development of eHealth in your country?

4. What are the priorities for the development of eHealth in your country?

5. What are the cultural factors influencing the development of eHealth in your country?

6. What is the link between ICT infrastructure and eHealth development in your country?

7. What is the link between eHealth 
systems and national health system in your country?

8. Provide evidence on eHealth by citations/ copies of surveys, scientific/technical studies, progress/special reports, eHealth education for the workforce.

9. Highlight of one or two shining examples from your country, such as adoption of a national eHealth policy, establishment of a health informatics education program, public-private partnership.

10. What are the lessons to be learned from the country's eHealth experience!

The survey method was selected as it allows for overview and to understand a problem and its reasons by quantifying certain aspects of it. Although trying to quantify certain phenomena the study is primarily intended to explore the given problem context in order to inspire to further, detailed research.

\subsection{Data Collection}

Representatives of the 32 national member associations of European Federation of Medical Informatics (EFMI) were identified via www.efmi.org, and invited to answer the questions listed above. The national representatives were asked to answer the ten questions on eHealth developments and experiences to reflect efforts their country, and contribute to describe current eHealth developments and experiences in Europe. The questionnaire was electronically sent to all national associations in July 2011. By October 2011 thirteen responses were received from EFMI members.

\subsection{Data Analysis}

The results presented here are based on the method of qualitative and quantitative content analysis [12] of the received material. The main goal of our analysis is to identify, abstract and quantify eHealth challenges in the answers to the posed questions. We started off to summarize the descriptions and definitions of eHealth, and continued to extract eHealth challenges. The eHealth challenges are defined as requirements, prerequisites, difficulties and obstacles encoun- tered in the development and implementation of eHealth in Europe.

As a first step, statements on potential challenges were extracted from all answers received, based on the above definition. Extracted statements were annotated and generalized by two researchers (WOH, AH). Generalized statements were again arranged into disjunctive categories by a team of four (WOH, AH, JH, AM). A consistent set of categories required three revision cycles. To validate the categorization set internally all initially extracted statements were assigned to the elaborated categories again. In addition, the number of statements assigned to each category was used to determine a relative weighting factor. This factor was used in the final step when we created the tag cloud presented as figure 1 .

\section{Results}

\subsection{Descriptions of the Concept of eHealth}

To better understand and appreciate the developments and initiatives across European countries in terms of eHealth it is necessary to establish a shared understanding of what is understood by the concept of eHealth.

Drawing from the responses in our survey there is consensus that eHealth primarily relates to the use and introduction of information and communication technology (ICT) but also to calls for cross-institutional and inter-disciplinary understanding of eHealth. The provided descriptions allude to previously reported potentials to meet emerging challenges to health care provision and improve the health system across Europe [c.f. 2, 13]. Privacy, security and the use of standards were given as important, general requirements for achievements in eHealth. We found agreement in the received material suggesting that future developments in eHealth require active integration to allow opportunities for participation by all citizens. eHealth should therefore not be restricted to health professionals.

eHealth has become a common name for design, development, implementation and evaluation of ICT in the health system, broadly understood. Collaborative thinking and new way(s) of working in healthcare require new forms of interactions to attend to the needs by stakeholders including health professionals, patients or their relatives. Three descriptions stated explicitly that eHealth is not just the use of ICT in health care, but should be considered broadly in relation to the plethora of needs within the healthcare system. ICT is an important, but not sufficient enabler to meet challenges in and to the national health care systems across Europe. In line with previously published descriptions of eHealth [c.f. 13, 14], the broader aim of eHealth is to support health professionals in their work and continuous, lifelong learning, as well as to assist all citizens in their own health care management and their search for reliable health information, disregarding organizational boundaries and functioning of the health systems.

The majority of the responses contained examples of important initiatives to provide high quality health information for use at the point of need. Specifically named services ranged from infrastructure for secure access to health data for the collaboration of providers and patients; repositories and suits of applications for digital, clinical records; and tools to actively encourage participation by patients. A striking finding in the responses to our survey is that similar types of applications and services are named differently. Likewise, the reports showed that infrastructure and connectivity to share information across different levels of care, between care facilities or providers, or patients and relatives are considerable challenges. Along the same lines, several connected deployment and use of services that enable citizen to access their health data securely and participate in their treatment, care and health prevention to the current state of (poor) Internet access for citizens.

\section{2 eHealth Services and Applications in Europe}

Overall, in their answers most representatives of EFMI's national member societies report on the importance of national 
leadership and a national eHealth strategy including administrative, professional and citizens' perspectives. In some countries regional strategies accompany the national strategy. The progress in deployment of services and applications varies. To elaborate on the deployment we clustered the reported initiatives as "technical and social eHealth infrastructure", "eHealth repositories" and "eHealth applications" based on the collected material.

Technical and social eHealth infrastructure would provide opportunities for secure, seamless transmission of health information between home care/primary care, hospitals and GPs, and between public and private health sector. Examples include efforts for data exchange and interoperability in terms of terminology, ontology and standard development, protocols for information sharing and semantic interoperability, as well as legal and ethical issues for correct authentication, confidentiality and maintained trust. eCards, eSignature, unique identifiers for patients and providers, and protocols for electronic exchange of health information are examples pointing to the technical and social eHealth infrastructure.

eHealth repositories would be Electronic Health Records and Patient portals. There is a plethora of labels reported including DMP, EPR, EHR, longitudinal medical record, eArchive or eView. Patients and healthcare professionals should be able to securely access resources in an eHealth repository for purposes of coordination, continuity, and self-management. A study from Germany and Austria indicates the high interest of patients respectively citizens in these technologies [15]. The DMP (dossier médical personnel) initiative in France illustrates interdependent efforts in terms of inter-operability, security of systems, organization of services and involvement of all stakeholders to develop a coherent e-health "ecosystem" [16]. The variety of different requirements to eHealth repositories respectively Electronic Health Records across Europe is covered in a systematic review by Hoerbst and Ammenwerth [17].

eHealth applications are specific services for workflow support and interaction between providers and patients across time and space given available eHealth infrastructures and repositories. Services like eReferral, Patient Summary and eDischarge, ePrescription and eMedication, eRadiology, eLaboratory, eCare Coordination and eSurveillance as well as Telemedicine and eServices for citizens are identified as building blocks.

Patient summaries and eDischarge applications offer a structured, focused summary of clinical findings from a health encounter. A study from Austria for example reports high satisfaction and positive impact of electronic communication of discharge letter between hospitals and GPs [18]. A survey from Scotland reports that eDischarge letter is faster and may lead to noteworthy cost savings [19]. ePrescription and eMedication refers to electronic support to the chain of actions in medication prescription. A study from Sweden reports that physicians were generally satisfied with their specific EHR-system and with the available ePrescribing functionality [20]. eReferral and eBooking automates the scheduling process to health care service. A survey from Scotland showed modest rates of adoption for e-referrals [21]. In a study of eRadiology, sharing MRI images between smaller and larger hospitals are reported as promising [22]. In the field of eMonitoring and telemedicine several studies from European colleagues report benefits for chronically ill patients. For example, telemonitoring of the lung function of patients affected by Cystic Fibrosis led to less hospitalization and reported economical saving [23]. Home spirometry for outpatient lung transplants showed that eMonitoring was feasible, safe, and decreased anxiety [24]. Telemedicine enabled eConsultation facilitates supervised care, reduction of outpatient visits and more timely appointments $[25,26]$. A study of telemedicine supported thrombolytic treatment of acute ischemic stroke in Denmark suggests that the macroeconomic costs may balance with savings in care and rehabilitation services within 2 years. Although long-term calculations are uncertain, potentially large long-term savings are associated with telemedicine support to this treatment [27]. In the area of eCoordination, evaluation of support for home care document improved communication, coordination and collaboration among nurses, psychologists and doctors
[28]. And lastly, in a study of eService for patients, the authors report that a personal health record (PHR) did not increase patient empowerment, but, at the same time, a PHR did not have any significant adverse effects either [29] .

\subsection{Challenges for eHealth Deployment}

Categorizing the reported challenges relating to eHealth deployment in Europe gives the following tag cloud (figure 1).

Figure 1 illustrates that quite heterogeneous challenges to eHealth deployment are reported in our survey. We acknowledge that there are several ways to interpret the collected information. For this presentation we choose to zoom in on four dimensions: 'strategy \& policy', 'organizational', 'professional' and 'technological'.

The reader of the tag cloud, figure 1, would be struck by the prominence of the strategy \& policy dimension. The importance of an appropriate legal framework and national strategy with sufficient funding is noticeable, and point towards a call for governmental priority to authorize eHealth bodies. Another finding is the strong national focus. Our respondents only mentioned the importance of international cooperation once. In terms of organizational dimension the importance to balance interest between private and public sector, involving and educating all stakeholders, handle persistence and initiate change management, and importance of driving forces for coordinated efforts stood out. Clustered as the professional dimension are issues that relate to inherent complexity of clinical practice and the variety of professional issues that surface following development and introduction of eHealth across Europe. The importance of traceable benefits visible to all parties and appropriate incentives can help overcome challenges of "silo thinking" and lack of cooperation. The technical dimension relates to efforts to establish a sound eHealth platform. Here the answers tap into well known challenges in the health informatics community, e.g., harmonize standards, support semantic interoperability, optimize 


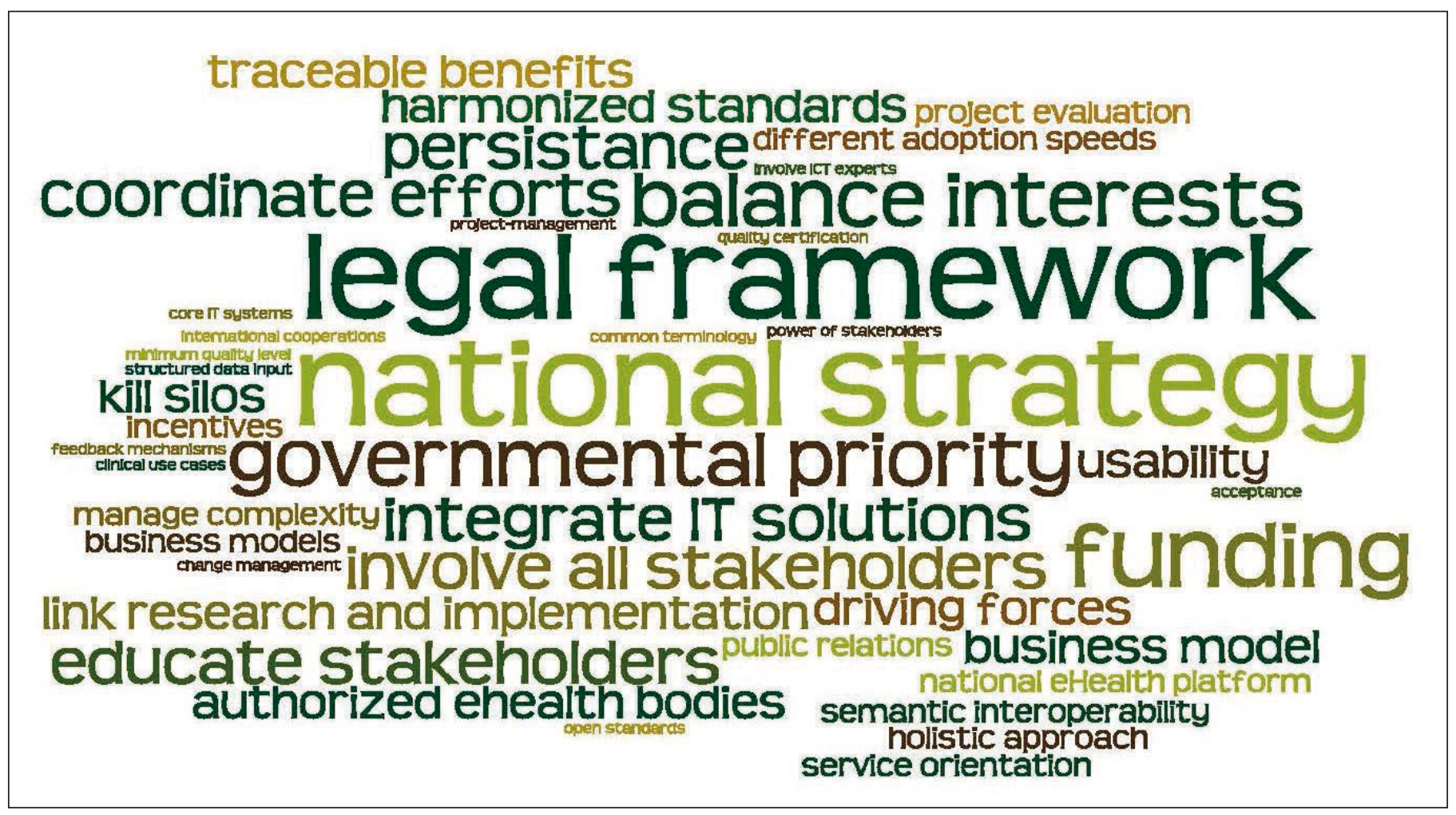

Fig. 1 ellealth challenges, relative frequency correlates with font size

usability for integration of new and existing IT-solutions demonstrating a service orientation, and support the mobility of patients and health professionals.

\section{Discussion \& Conclusion}

The findings from this study provide a broad overview of eHealth in Euorpe as an evolving field where there is a lot of activity. The answers report interesting national perspectives that add to previous reports [3]. The four dimensions identified in this survey are important starting points for further research and development to constitute progress in the eHealth area. The most important insight from this study is an urgent need to ensure that eHealth strategies and policies for further design and deployment of eHealth applications support sociable services and innovations in health care. Reported diversity in the current eHealth development and exploitation in Europe support a shift from a strict focus on ICT implementation to a com- prehensive, holistic approach. This approach would acknowledge that eHealth involves interplay of appropriate technical and social infrastructure, secure repositories and usable applications [5, 8]. The next steps would be to ensure that existing and new applications support sociable services and innovations in health care. More information about the interplay of product, project and impact evaluation to link research and implementation should be collected as evidence to enable learning from accumulating experiences.

Although this survey focused largely on national issues, the report highlights important challenges to overcome for future development of eHealth. We consider the emphasis on the policy \& strategic, organization, professional and technological dimensions related to eHealth as overlapping and highly interdependent. The implications would be that upcoming challenges should be approached and addressed by taking these dimensions into account [6]. Although the accumulated evidence demonstrates the complexity and importance of multiple interacting perspectives, more research on the interactions and implications of scientific findings for the everyday practice are needed for further achievements in eHealth.

There are obvious limitations to this survey, reflected in who responded and what they chose to highlight from their country to answer the questions. Lack of reference to the ongoing efforts within other countries as well as meager attention to European leadership can point in the direction of national eHealth silos. Priorities in eHealth may be perceived as a national issue, in line with health care as a national responsibility across Europe. However, priorities stated on the European level [30] most likely influence emphasis in eHealth policy and strategy nationally, and can be a leading force for progress across the region.

\section{Acknowledgements}

We acknowledge contributions from our colleagues in the EFMI community (alphabetic order); Britta Böckmann, Anita Burgun-Parenthoine, Nihal Dizdar, Valgerður Gunnarsdóttir, Mira Hercigonja-Szekeres, Antonis Jossif, Gunnar Klein, Sabine Koch, Oleg Yu 
Mayorov, George Mihalas, Ragnar Nordberg, Günter Schreier, and Brigitte Seroussi.

\section{Copyright information}

This article has already been published in EJBI 2012; 8(1):2-7. Reprinted with kind permission from the editors.

\section{References}

1. Haux R. Medical informatics: Past, present, future. Int J Med Inf. 2010;79(599).

2. Rigby M, Brender J, Beuscart-Zephir M, Hyppönen H, Nykänen P, Talmon J, et al. Next Steps in Evaluation and Evidence - from Generic to Context-Related, pp. 208-212. In: Moen A, et.al, editor. User-centred Networked Care. IOS Press; 2011.

3. van Gemert-Pijnen J, Nijland N, Van Limburg M, Ossebaard H, Kelders S, Eysenbach G, et al. A holistic framework to improve the uptake and impact of eHealth technologies. J Med Internet Res. 2010.

4. Stroetmann KA, Altmann J, Stroetmann VN, Protti D, Dumortier J, Giest S, et al. European countries on their journey to national eHealth infrastructures. Final Strategic Progress Report. Berlin, Germany: Empirica 2011.

5. Andreassen HK, Sørensen T, Kummervold PE. eHealth trends actoss Europe 2005-2007. Tromsø: National Center for Collaborative care and Telemedicine; 2007.

6. Moen A, Andersen SK, Aarts J, Hurlen P, editors. User Centred Networked Health Care. IOS Press; 2011.

7. Andersen SK, Klein, G, Schulz S, Aarts J, Mazzoleni MC, editors. eHealth Beyond the Horizon - Get IT There. IOS press; 2008.

8. Nøhr C, Aarts J, editors. Information Technology in Health Care: Socio-Technical Approaches 2010. From Safe Systems to Patient Safety. IOS Press; 2010.

9. Blobel B, Hvannberg E, Gunnarsdóttir V, editors. Seamless Care - Safe Care, The Challenges of
Interoperability and Patient Safety in Health Care. IOS Press; 2010.

10. Stoicu-Tivadar L, Blobel B, Marcun T, Orel A, editors. e-Health Across Borders Without Boundaries. E-salus trans confinia sine finibus. IOS Press; 2011.

11. van Limburg M, van Gemert-Pijnen JE, Nijland N, Ossebaard HC, Hendrix RMG, Seydel ER. Why Business Modelling is crucial in the development of eHealth technologies. J Med Internet Res. 2011;11(3):e41.

12. Mayring P. Qualitative Content Analysis. Forum Qualitative Sozialforschung/Forum Qualitative Social Research (serial on the Internet) 2000;1(2).

13. Eysenbach G. What is e-health? J Med Internet Res 2001;3(2):e20.

14. Eysenbach G. Medicine 2.0: social networking, collaboration, participation, apomediation, and openness. J Med Internet Res 2008;10(3).

15. Hoerbst A, Kohl C, Knaup P, Ammenwerth E. Attitudes and behaviors related to the introduction of electronic health records among Austrian and German citizens. Int J Med Inform. 2010;79(2):81-9.

16. ASIP Sánte. The DMP: a project that is structuring the development of e-health in France. 2010: [cited 2011 Nov 3] Available from: http://esante.gouv.fr/ en/dossiers/dmp-a-project-structuring-development-e-health-france.

17. Hoerbst A, Ammenwerth E. Electronic health records. A systematic review on quality requirements. Methods Inf Med 2010;49(4):320-36.

18. Machan C, Ammenwerth E, Schabetsberger T. Evaluation of the electronic transmission of medical findings from hospitals to practitioners by triangulation. Methods Inf Med 2006;45(2):225-33.

19. Pillai A, Thomas SS, Garg M. The electronic immediate discharge document: experience from the South West of Scotland. Inform Prim Care. 2004;12(2):67-73.

20. Hellström L, Waern K, Montelius E, Astrand B, Rydberg T, Petersson G. Physicians' attitudes towards ePrescribing--evaluation of a Swedish full-scale implementation. BMC Med Inform Decis Mak 2009;Aug(7):9-37.

21. Pagliari C, Donnan P, Morrison J, Ricketts I, Gregor P, Sullivan F. Adoption and perception of electronic clinical communications in Scotland.
Inform Prim Care 2005;13(2):97-104.

22. Marthinsen PB, Hald J, Bergstrøm R, Jakobsen J, Christensen D, Roterud H, et al. The multimedia, virtual MR imaging department, clinical aspects. Int J CARS. 2009;3(S1):155-63.

23. Murgia F, Cilli M, Renzetti E, Popa N, Romano T, Alghisi F, et al. Economic evaluation of telehomecare in chronic lung diseases. Clin Ter 2011;162(2):e43-9.

24. Sengpiel J, Fuehner T, Kugler C, Avsar M, Bodmann I, Boemke A, et al. Use of telehealth technology for home spirometry after lung transplantation: a randomized controlled trial. Prog Transplant 2010;20(4):310-7.

25. Harno K, Ruotsalainen P. Sharable EHR systems in Finland, pp. 364-70. In Bos, L et.al. editors. Medical and Care Compunetics 3, IOS Press; 2006

26. Nijland N, van Gemert-Pijnen JE, Boer H, Steehouder MF, ER. S. Increasing the use of e-consultation in primary care: results of an online survey among non-users of e-consultation. Int J Med Inform 2009;78(10):688-703.

27. Ehlers L, Müskens WM, Jensen LG, Kjølby M, G. A. National use of thrombolysis with alteplase for acute ischaemic stroke via telemedicine in Denmark: a model of budgetary impact and cost effectiveness. CNS Drugs 2008;22(1):73-81.

28. Pitsillides A, Samaras G, Pitsillides B, Georgiades D, Andreous P, Christodoulou E. DITIS: Virtual Collaborative Teams for Home Healthcare. J Mob Multimedia 2006;2(1).

29. Tuil W, Verhaak C, Braat D, de Vries Robbe P, Kremer J. Empowering patients undergoing in vitro fertilization by providing Internet access to medical data. Fertil Steril 2007;88(2):361-8.

30. Commission of the European Communities. Communication from the Commission to the Council, the European Parliament, the European Economic and Social Committee and the Committee of the Regions: e-Health - making health care better for European citizens: An action plan for a European e-Health Area. Brussels; 2004.

\section{Correspondence to:}

Anne Moen

P.0.Box 1130, Blindern

$\mathrm{N}-0318$ Oslo, Norway

E-mail:anne.moen@medisin.uio.no 